\title{
Detailed analytical methods for simulation of concrete target resistance against F-4D jet impact
}

\author{
Thomas H.K. Kang ${ }^{{ }^{*}}$, Joon-Ki Hong ${ }^{2}$ \\ 1,2 Department of Architecture and Architectural Engineering, Seoul National University, Seoul, Korea
}

\author{
Keywords \\ Finite element analysis \\ F-4D jet impact \\ Concrete target \\ Simulation
}

Received: 2 January 2018

Accepted: 23 January 2018

Published: 13 February 2018

\begin{abstract}
The major concerned objective of this paper is to suggest more detailed analytical methods to simulate the projectile impact on concrete target using the finite element analysis software of ANSYS LS-DYNA. The concrete is a principal material that has been comprehensively used in the field of civil and architectural engineering including from high-rise structures to long-span bridges. Not only these typically representative buildings, but other structures and national major facilities, such as nuclear power plants, also have mainly adopted concrete in various ways. These concrete structures should be designed against severe accidents causing structural failure. In this regard, the structural safety of each concrete structure should be evaluated meticulously. Detailed analytical methods are suggested by establishing numerical models in the software, which are used to simulate actual experiments in the past, F-4D jet impact experiments conducted by Sandia National Laboratories in 1988.
\end{abstract}

(C) 2018 The Author(s). Published by TAF Publishing.

\section{INTRODUCTION}

Concrete is a material that has been comprehensively utilized in civil and architectural construction of from highrise structures to long-span bridges. Diverse development methods also have been studied actively. As various concrete structures provide people with a living space, these let the people feel more comfortable and help them to avoid the danger of accident from the external environment. Not only these typical buildings and bridges, but other structures, such as government major facilities, also mainly adopt concrete materials in various ways.

As shown in Figure 1, World Trade Center (WTC), the building deemed as an emblem of U.S., was collapsed by the impact of hijacked aircrafts. After this horrible terror, numerous research programs have been widely studied to guarantee the structural capacity against the impact of accidents on NPPs. Even though it rarely seems to be directly correlated with NPPs, the U.S. Nuclear Regulatory Commission (NRC) classified the impact incidents as a Beyond Design Basis Event (BDBE) [1].
Researchers could recognize the importance of the aircraft accidents from the 9/11 attack. Moreover, the importance of structural redundancy for an earthquake has been emphasized again since the Tohoku disaster in 2011. In this way, regulations related to NPPs have been enhanced based on variable extreme loadings beyond the design criteria obtained from actual accidents, although it has an extremely low probability to happen. For securing safety, the previous incidents have been reflected in the development and revision of regulations. The information obtained from manifold accident cases has been utilized as acceptance criteria of the regulations. As a result, it has been employed in existing or newly constructed containments. It has significantly contributed to the improvement of safety for nuclear containment structures [2].

Not only the aircraft impact cases, but also a wide variety of projectile impacts on concrete target are urgently necessary to be researched in the field of protection engineering and/or military industry. Variable studies relevant to the projectile impacts will continuously be conducted.

\footnotetext{
${ }^{*}$ Corresponding author: Thomas H.K. Kang

†email: tkang@snu.ac.kr
} 
The primary purpose of this study is to suggest detailed analytical methods to simulate the F-4D jet impact on a concrete target using the finite element software, ANSYS LSDYNA. Moreover, there is a need to verify previously suggested methods with the assumption of a concrete target including concrete containment structures and various concrete structural walls. Detailed analytical methods are suggested by establishing several numerical models in the software to simulate the actual experiments about aircraft impact conducted by Sandia National Laboratories in 1988. The reliability of the approach is evaluated by comparing the simulated results with the experimental results.

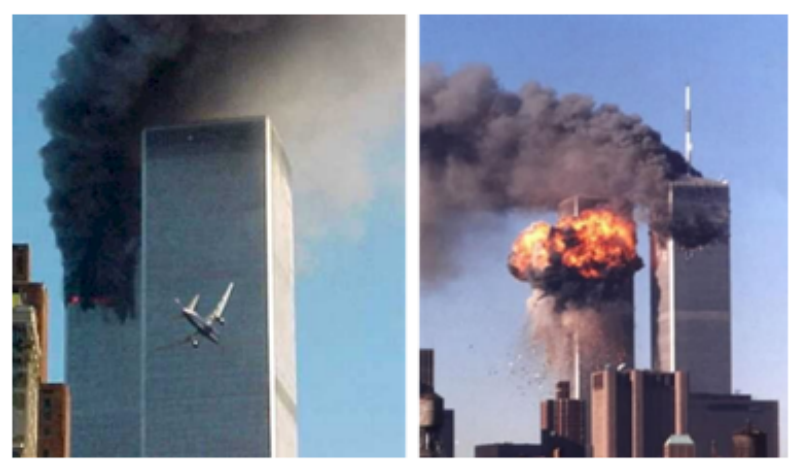

Fig. 1. Aircraft attacks on world trade center in 2001

\section{SUMMARY OF F-4D JET IMPACT TEST}

In 1988, a full scale F-4D Phantom jet impact test was conducted by Sandia National Laboratories (SNL) using their own facilities. One of the primary objectives of this experiment is to solve the questions that previous theoretical approaches left.

It was also to determine an array of the responses to the aircraft considering uncertainties not involved in previous methods. Lastly, to make relatively accurate predictions of impact force is the other aim of this experiment. The SNL had a facility which was $600 \mathrm{~m}$ long two rocket rails. The representative F-4D Phantom jet, which had a weight of 469 tons at a speed of $215 \mathrm{~m} / \mathrm{s}$, crashed into a rigid reinforced concrete block. Some equipment in the F-4D model was removed to be carried on the rail, while sleds and rockets were attached. For instance, seats, gears, and flaps at the main wings were removed, whereas sled and rockets were added. As a result, the total impact weight of the aircraft was 19 tons. The massive reinforced concrete target had $7 \mathrm{~m}$ of height and width, and $3.66 \mathrm{~m}$ of thickness. The weight of the target was 469 tons, approximately 25 times of the F-4D aircraft. Through five instrumentations, the impact responses of the target were recorded, including velocity, acceleration, and displacements. Major test results were described in the published paper $[3,4,5]$.
Figure 2 depicts the procedure of the aircraft impact. From the experiment, it was confirmed that the damage caused by the aircraft impact was not critical for the concrete target. It was speculated that most of the energy was used to move the target rather than causing significant damage on the target. Considering these perspectives, an additional experiment was conducted [6]. Furthermore, the accuracy of Riera function was verified, showing reliable results in the event of impact accidents. It was defined that the acceptable effective coefficient for mass is 0.9 through the experiment. What it means is that $10 \%$ of the projectile mass would be reduced during the impact. Finally, it was concluded that the impact area of the structure subjected to impact load can be measured as approximately twice the fuselage area.
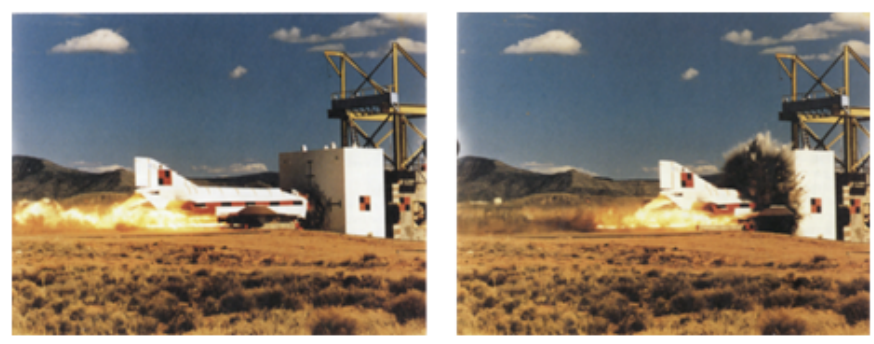

Fig. 2. F-4D Jet Impact on Concrete Target [4]

\section{DETAILS OF ANALYTICAL METHODS IN FEA SOFTWARE}

Missile-Target Interaction Analysis (MTIA) is a method using the finite element analysis. Using the MTIA, users can perform diverse analyses explicitly with a model combined with targets and projectiles [7]. This method has been referred to consider variable circumstances which are significantly difficult to be conducted in actual tests. The amount of studies has been on the rise with explicit analysis using computational analysis programs, including AUTODYN, ABAQUS, and ANSYS LS-DYNA. Combinations of targets and crushing projectiles are established in the diverse programs to observe a wide variety of structural nonlinear performances. The impact process can be activated by the defined initial velocity of the projectile.

For F-4D Phantom jet, the Smoothed Particle Hydrodynamics (SPH) without any mesh were applied to consider large deformations during the impact. Due to disconnected particles between each other, the particles were spread out at impact. Therefore, it is possible to consider secondary effects of debris or fuel [8]. The 3-dimensional F-4D model was given as STL file. It is imported into LS-DYNA through the PrePost. The initial model was made of shell elements for only the external shape, while the inside of the shell was 
empty. Instead, SPH particles were filled inside the shell using SPH generation function in ANSYS LS-DYNA.

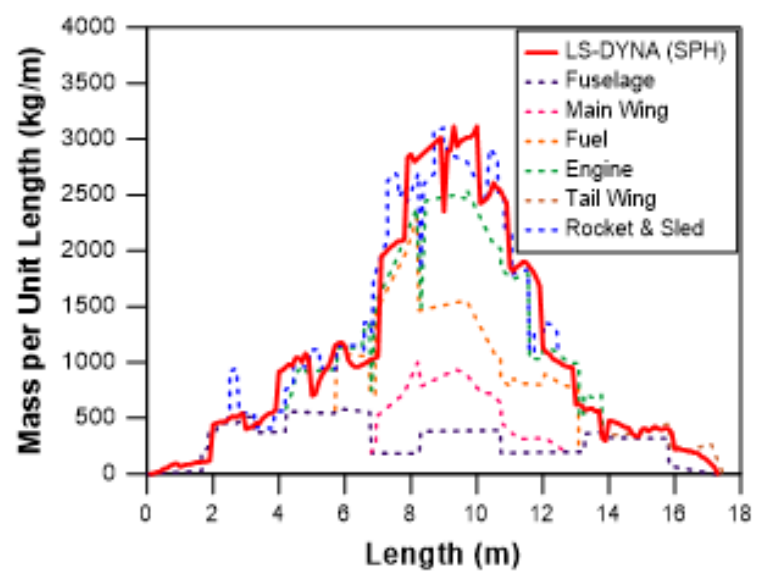

Fig. 3. Mass distribution comparison with test

The basic concept in aircraft modeling in this study was that F-4D Phantom only consists of same materials with SPH elements. In other words, there are no classifications about various materials, such as engine, fuel, or fuselage. Mass for each length was differentiated to combine multiple mass distribution of several parts. First of all, SPH elements were generated through LS-PrePost. It was divided into several parts along with the unit length $(1 \mathrm{~m})$ of the F-4D Phantom model to introduce mass information at each length. For matching with the mass distribution for an actual test, numerous values for mass were determined at particles since each length had different number of SPH elements. The mass per unit length could be determined for the number of elements multiplied by the introduced mass value. Figure 3 represents the comparison of mass distribution between the experiment and analysis in this study, and illustrates commensurate outcomes in terms of the mass distribution compared to the actual test. Therefore, it can be concluded that the aircraft model constructed in ANSYS LS-DYNA is valid to conduct the impact simulation.

Aluminum was assumed as a material for the F-4D jet using plastic kinematic model (MAT_003) in ANSYS LS-DYNA as well as for the reinforcement model. In this study, the Failure Strain (FS) of 1.8 was applied according to the results performed by [9]. Even though some inserted conditions are quite different from the previous study, such as contact conditions, components, properties, it can be applied in this model as well.

For concrete target, foundation mat and platform were neglected in this analysis in order to simplify the analysis conditions. A concrete block directly collided with the aircraft was merely established in ANSYS LS-DYNA. As a bound- ary condition, the target was assumed such that it can only move to the direction corresponding to the F-4D jet path crashing into the target. Therefore, restraint of the direction, along which the aircraft would move, was released. ANSYS LS-DYNA provides several material types to establish concrete models. For instance, MAT_024 (Piecewise Linear Plasticity Model), MAT_072 (Karagozian and Case Concrete), MAT_084 (Winfrith Concrete), MAT_111 (Johnson-Holmquist Concrete), and MAT_159 (CSCM) are frequently used in analysis corresponding to the concrete material. For observing various characteristics for concrete models, the MAT_159 concrete material model was employed in this study. The CSCM concrete model was developed for analysis about impact or blast. Its validations have been already done by a wide variety of studies [10]. The CSCM concrete model has elastic-softening behavior steps for stress-strain relationship [11]. It can demonstrate peak strength under no confinement. Also, post-peak softening and brittle ductile transition are illustrated, but with low accuracy. It has a tendency to be ductile in the event of pressure loading and little influenced by the effects of the strain rate. In addition, it is stiff under blast, while good agreements can be derived for impact loading. The compressive strength should be determined between $20 \mathrm{MPa}$ and $58 \mathrm{MPa}$, while the maximum aggregate size should be set to between $8 \mathrm{~mm}$ and $32 \mathrm{~mm}$. Based on the compressive strength, the stiffness, three-dimensional yield strength, hardening, and softening are determined. Meanwhile, the maximum size of the aggregate is needed only for the softening behavior of the damage formulation [12].

The principal difference between other concrete models is the failure criteria that are implemented in the CSCM concrete model as ERODE card. It is a parameter that users can easily manage to model the failure of concrete. Erosion of the concrete is activated based on a determined erosion coefficient in this card. With respect to the erosion factor, unity means the erosion is independent of the strain, while the erosion coefficient is less than unity, the erosion of the concrete never takes place [13]. The erosion coefficient at zero also indicates no erosion effects. If the erosion value is greater than unity, the concrete elements will be failed once the strain reaches the maximum principal strain. For instance, 1.1 of the erosion coefficient means that the concrete elements have the maximum principal strain of $10 \%$. Some elements, which exceed the specified maximum principal strain, will be deleted. In general, the erosion coefficient is determined between 5 and 10 percent of maximum principal strain [12].

MAT_003 (PLASTIC_KINEMATIC) material model was 
widely employed as the reinforcement. It was generated as a truss element considering conservative aspect [10]. If the reinforcements are constructed as a beam element, the behavior of the reinforcement can be underestimated due to the resistance to flexural behavior. The analysis time can be reduced using the truss element for reinforcement steel because reinforcement elements only resist axial deformation. As specific information about embedded reinforce- ments was not provided, D-13 steel was basically assumed in the analysis. The CONSTRAINED_LAGRANGE_IN_SOLID keyword was used to simulate reinforcements embedded in the concrete by setting reinforcement steel as a slave part, while the concrete element as a master part. All material properties involved in the numerical analysis are summarized in Table ??.

TABLE 1

MATERIAL PROPERTIES FOR NUMERICAL ANALYSIS

\begin{tabular}{lcccccc}
\hline \hline Material & $\begin{array}{c}\text { Density } \\
\left(\mathrm{kg} / \mathrm{m}^{3}\right)\end{array}$ & $\begin{array}{c}\text { Modulus of } \\
\text { Elasticity (GPa) }\end{array}$ & $\begin{array}{c}\text { Compressive } \\
\text { Strength (MPa) }\end{array}$ & $\begin{array}{c}\text { Yield } \\
\text { Stress (MPa) }\end{array}$ & $\begin{array}{c}\text { Poisson's } \\
\text { Ratio }\end{array}$ & $\begin{array}{c}\text { Failure } \\
\text { Strain }\end{array}$ \\
\hline \hline $\begin{array}{l}\text { Aluminum } \\
\text { (MAT_003) }\end{array}$ & 2770 & 69 & - & 95 & 0.33 & 1.8 \\
$\begin{array}{l}\text { CSCM (MAT_159) } \\
\text { Reinforcement }\end{array}$ & 2615 & - & 30 & - & - & - \\
(MAT_003) & 7850 & 200 & - & 420 & 0.3 & 0.2 \\
\hline \hline
\end{tabular}

Particles consisting of the F-4D model were defined using DEFINE_BOX keyword. Using this keyword, the particles located outside the specified box were not considered during the analysis. In this regard, it is possible to reduce computational cost. For impact condition between the SPH modeling and the target, CONTACT_AUTOMATIC_NODE_TO_SURFACE keyword was applied. The aircraft SPH elements were defined as slave parts, whereas master parts were set to the concrete target, including steel reinforcements. The velocity was 215 m/s using INITIAL_VELOCITY keyword, which can introduce part speed easily.

\section{VARIOUS SIMULATION RESULTS}

The cardinal objective of using the Riera function is to calculate the impact force for aircrafts. At first, the impact force drawn from the Riera method was conducted based on the given mass distribution condition.

In Figure 4, the solid lines are the impact force of an aircraft in ANSYS LS-DYNA derived from the modified Riera function, while the dashed lines imply the results of the experiment. The aircraft impact force derived from the experiment was calculated from the Riera function, including crushing force, while the target force was directly derived from the recorded data from the test. On the other hand, the impact force for the aircraft in this study showed similar tendency along with the mass distribution. The total duration of impact calculated by the Riera function was close to both the experiment and the results in this study because the Riera function is an approximate solution. The differences in magnitude were due to the crushing force.

At near 0.02 seconds, the impact force of the concrete target was slightly decreased and then rapidly increased up to the peak value at 0.04 seconds when the heaviest part of the aircraft reached the target. Considering that the heaviest part of the aircraft was approximately $9 \mathrm{~m}$ from the front of the aircraft, this part was estimated to reach the target at 0.042 seconds by dividing by the initial velocity of $215 \mathrm{~m} / \mathrm{s}$.

There are two reasons why the impact force was diminished at 0.02 seconds. First of all, the impact force significantly depended on the mass distribution of the F-4D jet. According to Figure 3, rocket and sleds were added at $3 \mathrm{~m}$ from the front of the aircraft. It means that this minor mass of the projectile can affect the records of the test; therefore, it is important to match the mass distribution of the numerical model with the mass used in the test.

The second reason is that the impact force was affected by the reaction behavior of the concrete at the same time when the target was impacted. According to [14], the concrete target gives off compressive wave against the impact force which reaches the rear surface of the target. In this way, the rear region shows compressive behavior followed by steady region when the compressive wave is almost equal to the tensile wave. In this experiment and numerical simulation, the scabbing failure of the concrete target was not recorded. Therefore, the decrease of the impact force at 0.02 seconds was due to the compressive wave by the inside of the concrete opposite to the impact direction. Then, this wave was immediately cancelled off because the huge mass of the aircraft was crushing into the target. Moreover, the scabbing failure was difficult to occur since the thickness of the target was $3.66 \mathrm{~m}$. 


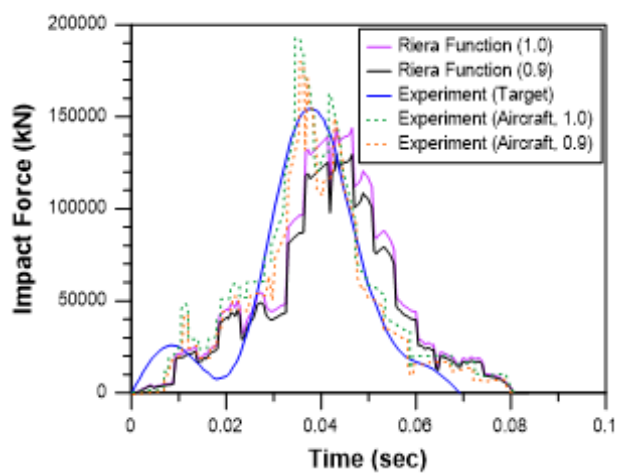

Fig. 4. Impact force from Riera function

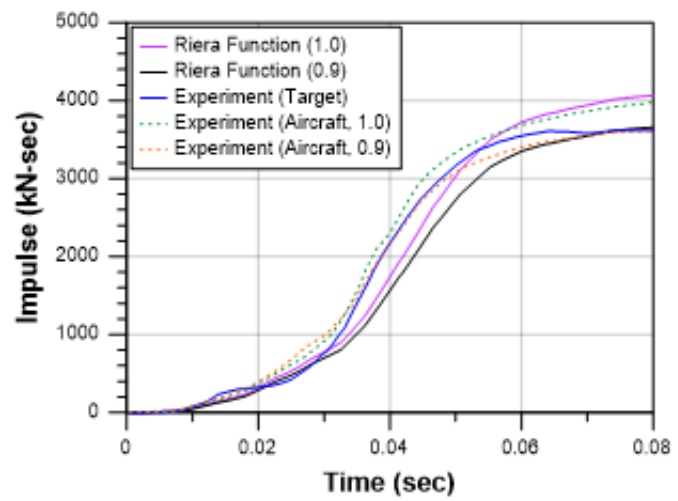

Fig. 5. Impulse from Riera function

The impulse results are demonstrated in Figure 5, which were calculated by integrating the impact force over time. Parts of the delayed impact force are reflected in the impulse near 0.04 second as shown in Figure 5 to Figure 6. The impulse using the Riera function illustrates a similar pattern to that of the impulse in this study. This means that the mass distribution established by ANSYS LS-DYNA was significantly analogous to that of the F-4D model used in the experiment. It is concluded that Riera formula is accurate to evaluate the impact force for the projectile, and it is verified that $90 \%$ of the mass would be reflected during the impact. However, key results from the experiment are not response of the aircraft, but that of the target because the impact force of the aircraft evaluated by the Riera function contains distributed mass during the impact. This is why the effective mass coefficient was introduced in the Riera function. It is necessary to compare results from analysis with responses of the target from the experiment as well as the results for mass distribution with the effective mass coefficient of 0.9 .

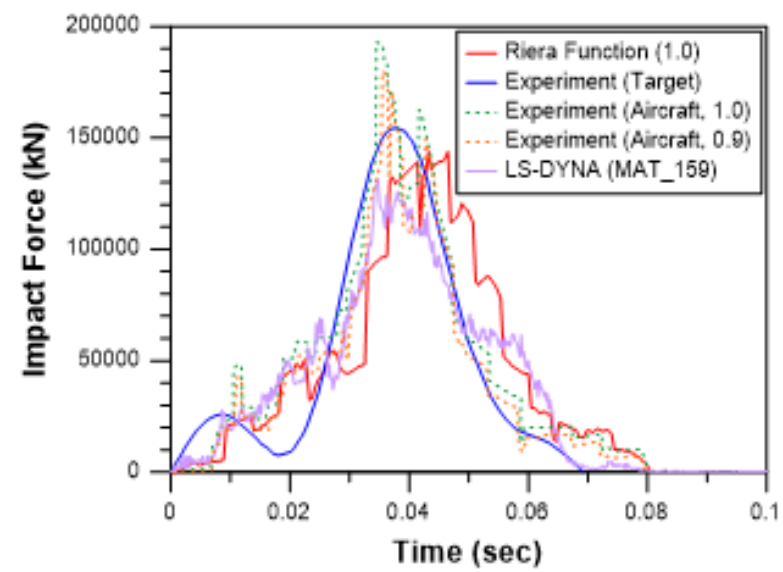

Fig. 6. Impact force from numerical analysis 


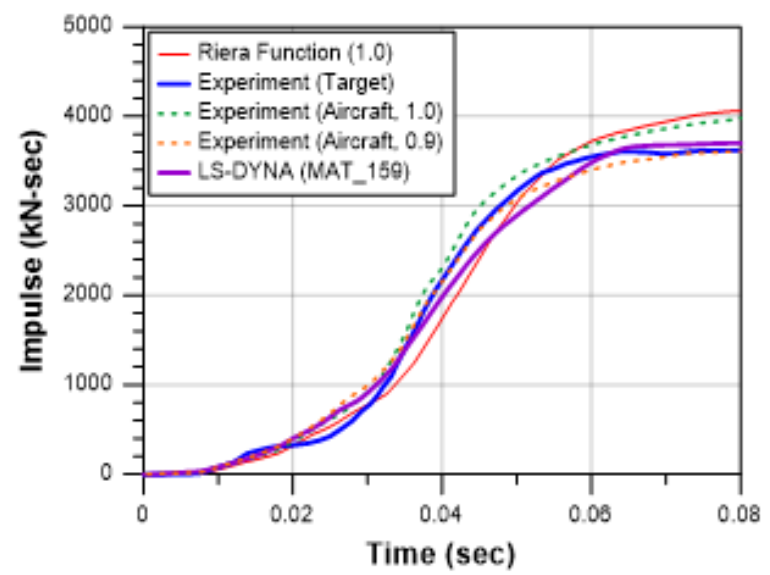

Fig. 7. Impulse from numerical analysis

Figure 6 depicts impact force of the numerical analysis compared to the experimental results and impact force derived from the Riera formula. The main object of the analysis was to compare the analytical results to the experimental results of the target since the target's behavior was mainly concerned. As shown in Figure 5, the tendency of the numerical results was similar to the experimental results. Figure 7 describes the impulse which was obtained by integrating the impact force along with time. The impulse from the numerical analysis shows considerable analogy with the experimental results. Furthermore, the numerical result is almost the same as the impulse of the aircraft with the effective mass coefficient of 0.9 .

In conclusion, from Figure 6 and Figure 7, it is concluded that the impact force and impulse derived from analysis results of ANSYS LS-DYNA are analogous to the Riera function. The Riera evaluation shows exactly the same pattern of mass distribution of the SPH model. It is because the assumption of the Riera method is that a projectile crushes into a rigid target and remains perpendicular to incidence. On the other hand, for reality and during the analysis, crushing parts can be affected by surrounding situations. It shows similar graphs between the analysis result and the Riera function. At 0.06 seconds, the impact force was dramatically decreased. It is regarded due to reflected and penetrated particles during the simulation. The numerical analysis in this study estimated the impact force correctly, and the result was reliable compared to the Riera approach.

As a further analysis, the tendency of the impact force and the impulse was figured out according to the various values of the FS parameter. According to [9], the FS of 1.8 displayed accurate results compared to others. However, the defined models between [9] and this study were different in terms of the specified properties or the conditions of the numer- ical aircraft model. The FS parameter implemented in the material keywords means the effective plastic strain when the elements start to be eroded [15].

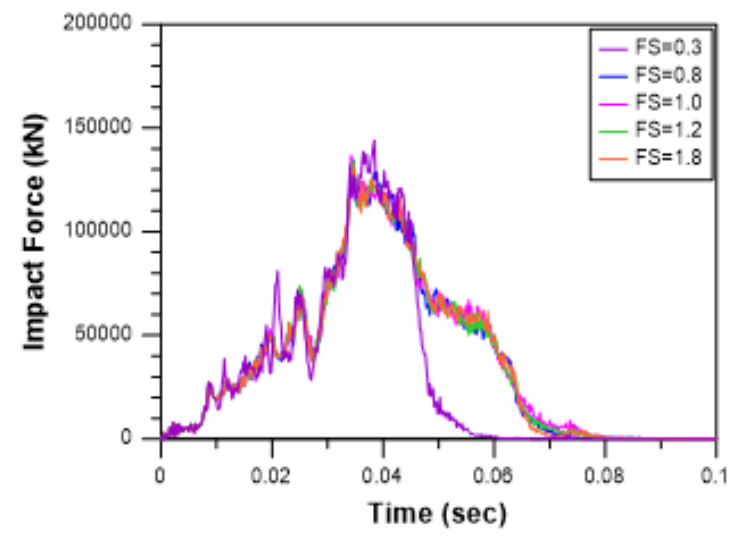

Fig. 8. Impact force with various FS

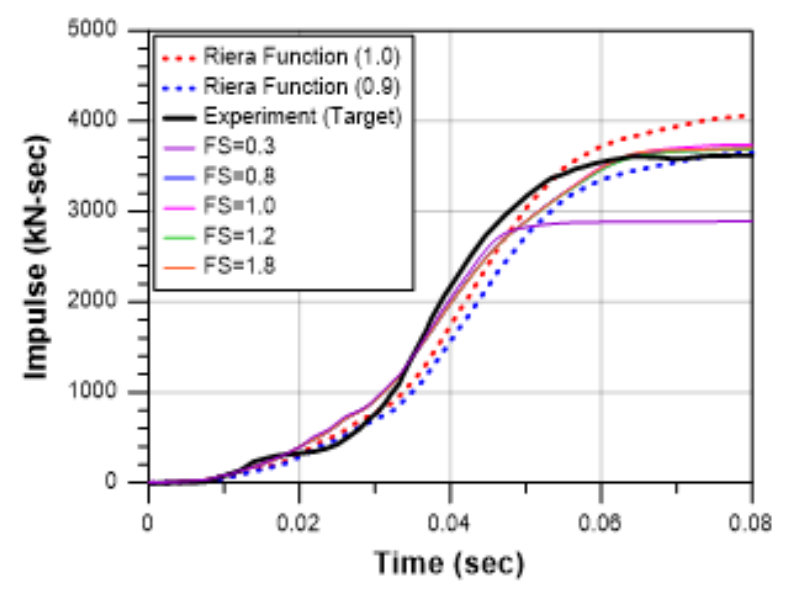

Fig. 9. Impulse with various FS

The selected values of the FS were $0.8,1.0,1.2$, and 1.8. As shown in Figure 8, the results of the impact force along with the various FS parameters were close to each other. It was 
assumed that the FS was not influential in the analysis to match with the test results. Even though [9] discussed the most appropriate value of the FS, the determined conditions in the software would be different in various ways. Therefore, with the numerical conditions in this paper, the FS was not concerned as a major parameter in the analysis.

Figure 9 illustrates comparisons for the impulse in terms of the diverse value of the FS. The result derived from the Riera function with the effective coefficient of 0.9 showed good agreement with the test result. Numerical results were almost the same regardless of the FS, and were located between the two results determined by the Riera function with different effective mass coefficient. It means that the numerical results showed variations within $10 \%$ from the experimental results. Therefore, any FS parameters used in this further study can be adopted since the results with the variation of $10 \%$ were roughly regarded as reliable conclusions.

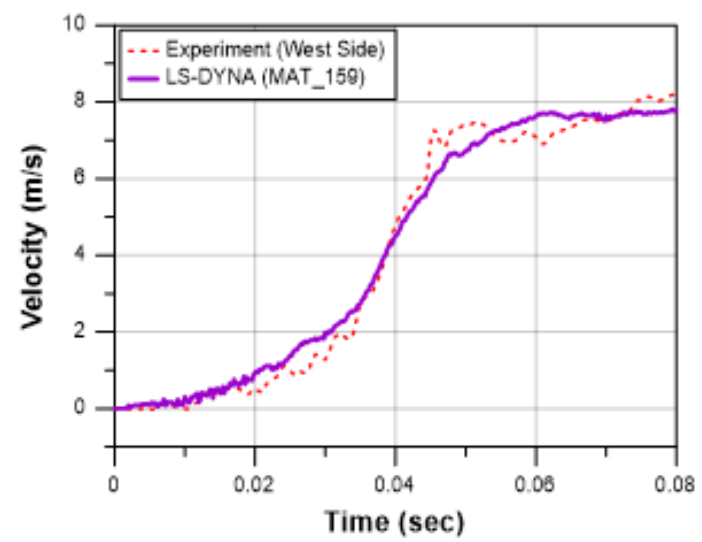

Fig. 10. Velocity comparison with test

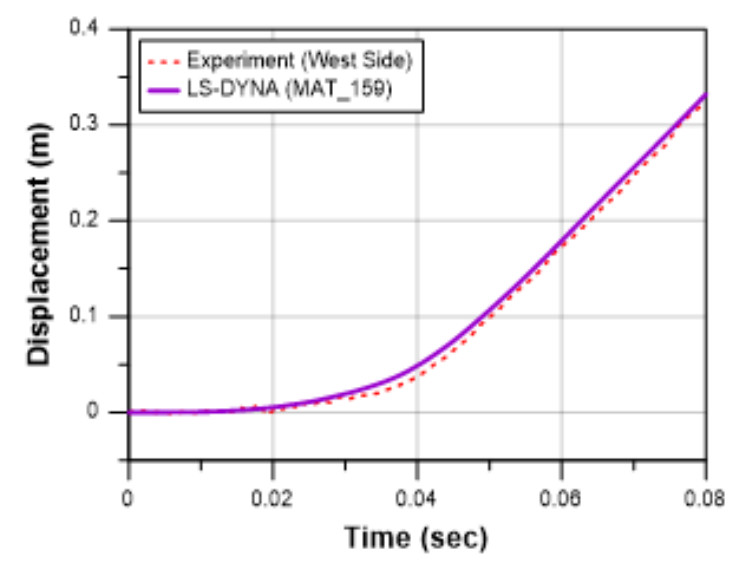

Fig. 11. Displacement comparison with test

The velocity and displacement of the concrete target are demonstrated in Figure 10 and Figure 11 respectively. It shows considerably similar patterns for both categories be- tween the experiment and the analysis. Around $0.04 \mathrm{sec}-$ onds, when the maximum impact force was recorded, both velocity and displacement rapidly increased. In summary, the numerical analysis using ANSYS LS-DYNA can illustrate impact accidents with accurate results. In this regard, numerical analysis using ANSYS LS-DYNA is reliable.

Overall, the CSCM concrete model in ANSYS LS-DYNA showed good agreement with the performance of the target. The aircraft behavior was agreed well with the effective mass coefficient of 0.9. The numerical model using the SPH method is similar to the actual aircraft behavior.

At the end of the simulation, concrete elements were deleted. In comparison to the test target, the penetrated shape is similar to the results of the test. The bottom of the impacted area was slightly different due to discrepancies in conditions between the analysis and the test. According to the Riera method, the total impacted area was regarded as twice the impact area of the projectile. For the experiment, the crushed area of fuselage of the F-4D aircraft was approximately $4.6 \mathrm{~m}^{2}$, while the impacted area of the target was 10 $\mathrm{m}^{2}$. In this study, the simulated impacted area of the target was approximately $10.14 \mathrm{~m}^{2}$ which is quite close to that of the experiment. These results give more confidence regarding the accuracy of the ANSYS LS-DYNA analysis and indicate the prediction capibility of the Riera method.

\section{SUMMARY AND CONCLUSION}

The primarily concerned subject addressed in this paper is to investigate the behavior of concrete structures under the aircraft impact. In addition, the validity of Missile-Target Interaction Analysis (MTIA) method is confirmed by comparison with the Riera formula and the results of the experiment. In ANSYS LS-DYNA, there are several types of concrete models with different characteristics. In this study, MAT_159 was selected as a concrete material. The primary conclusions and perspectives drawn from the present study are summarized as follows:

1) The Riera function is a typical approximate solution to evaluate impact force. It is based on the mass distribution of the projectile. In this study, the developed SPH aircraft model was consisted of several parts with unit length. Based on this mass distribution, the impact force derived from Riera formula showed good agreement with the results of the test. In addition to the Riera function, for getting more accurate solutions, the effective mass distribution factor $(\alpha)$ was introduced. From previous research, it was concluded that 0.9 is the suitable coefficient value for effec- 
tive mass distribution. As a result, its reliability has been confirmed from this study.

2) At 0.02 seconds, the impact force for the experiment showed slightly diminished tendency. The speculated reasons were the mass distribution of the jet used in the test and the reaction response of the concrete target. From the results, it was speculated that the determined mass distribution of the projectile could influence the results. In addition, according to the previous study performed by [14], the concrete generally shows compressive reaction opposite to the impact force. After that, the steady state was monitored as a result of the tensile wave due to the impact force. Considering that the target had the thickness of 3.66 $\mathrm{m}$, the scabbing failure was not easy to be happened.
3) With respect to the material properties of the aircraft, variable FS values can be determined in various ways. For this analysis, the FS of 1.8 was adopted because it was demonstrated to provide more reliable results than the others. Lastly, the aforementioned conditions helped to evaluate impact force so that ANSYS LS-DYNA analysis produced relatively accurate results. In addition to the aircraft impact accidents, it can be extensively expanded into other types of impact simulations.

\section{ACKNOWLEDGMENT}

This study was supported by the Institute of Research at Seoul National University.

\section{REFERENCES}

[1] The Nuclear Energy Institute, "Methodology for performing aircraft impact assessments for new plant designs," 2009. [Online]. Available: https://bit.ly/2jJqdTV

[2] I. H. Moon and C. S. Choi, "Structural characteristics and design specifications of nuclear power plant structures," Review of Architecture and Building Science, vol. 58, no. 7, pp. 12-22, 2014.

[3] D. S. Hasan and I. Hamarash, "Calculation of angular velocity, angular acceleration and torque of two common point rigid bodies using IMU," Journal of Applied and Physical Sciences, vol. 3, no. 2, pp. 58-64, 2017. doi: 10.20474/japs-3.2.3

[4] T. Sugano, H. Tsubota, Y. Kasai, N. Koshika, S. Orui, W. Von Riesemann, D. Bickel, and M. Parks, "Full-scale aircraft impact test for evaluation of impact force," Nuclear Engineering and Design, vol. 140, no. 3, pp. 373-385, 1993. doi: 10.1016/ 0029-5493(93)90119-t

[5] Y. L. Yeh and C. H. Chiang, "Sequence behavior of vortical development and evolution of a low-speed rectangular jet," Journal of Advances in Technology and Engineering Research, vol. 3, no. 4, pp. 144-149, 2017. doi: 10.20474/jater-3.4.4

[6] T. Sugano, H. Tsubota, Y. Kasai, N. Koshika, H. Ohnuma, W. Von Riesemann, D. Bickel, and M. Parks, "Local damage to reinforced concrete structures caused by impact of aircraft engine missiles part 1. test program, method and results," Nuclear Engineering and Design, vol. 140, no. 3, pp. 387-405, 1993. doi: 10.1016/0029-5493(93)90120-x

[7] IAEA, "Safety standard series: External events excluding earthquakes in the design of nuclear power plants, safety guide no. ns-g-1.5." 2003. [Online]. Available: https://bit.ly/2jJqdTV

[8] M. Kostov, M. Miloshev, Z. Nikolov, and I. Klecherov, "Non-structural mass modeling in aircraft impact analysis using smooth particle hydrodynamics," in 10 th European LS-DYNA Conference, Salzburg, Austria, 2015.

[9] K. Lee, J.-W. Jung, and J.-W. Hong, "Advanced aircraft analysis of an f-4 phantom on a reinforced concrete building," Nuclear Engineering and Design, vol. 273, pp. 505-528, 2014. doi: 10.1016/j.nucengdes.2014.02.032

[10] D. W. Seo and H. C. Noh, "Aircraft impact analysis of steel fiber reinforced containment building," Journal of the Computational Structural Engineering Institute of Korea, vol. 26, no. 2, pp. 157-164, 2013. doi: 10.7734/coseik.2013.26.2.157

[11] Y. Wu, J. E. Crawford, and J. M. Magallanes, "Performance of ls-dyna concrete constitutive models," in $12^{\text {th }}$ International Conference LS-DYNA Users, Detroit, MI, 2012.

[12] Y. D. Murray, A. Y. Abu-Odeh, and R. P. Bligh, "Evaluation of ls-dyna concrete material model 159," Federal Highway Administration, McLean, VA, Tech. Rep., 2007.

[13] A. M. Remennikov and S. Y. Kong, "Numerical simulation and validation of impact response of axially-restrained steel concrete steel sandwich panels," Composite Structures, vol. 94, no. 12, pp. 3546-3555, 2012. doi: 10.1016/j.compstruct. 2012.05.011

[14] T. H. K. Kang, S. Kim, M. S. Kim, and S. G. Hong, "Impact resistance of UHPC exterior panels under high velocity impact load," Journal of the Korea Concrete Institute, vol. 28, no. 4, pp. 455-462, 2016. doi: 10.4334/jkci.2016.28.4.455

[15] LSTC, "LS-DYNA keyword user's manual, livermore software technology corporation," 2016. [Online]. Available: https://bit.ly/2wCzpTt 